\title{
LA RESPONSABILIDAD SOCIAL Y LAS ESTRUCTURAS DE PODER
}

Tulio Ernesto Magaña M. Doctor en Ciencias Sociales Universidad del Zulia, Venezuela tuliomagana@avanceydesempeno.com

Recibido 20/07/2015

Aceptado 17/02/2016

\section{Resumen}

Este artículo hace un análisis de los orígenes del fenómeno denominado Responsabilidad Social Corporativa (RSC) y cómo éste ha sido determinante en las relaciones de poder entre el Estado y las empresas. La RSC surge del modelo neoliberal, es decir, de una tendencia a disminuir las funciones del Estado en un contexto mercado-centrista, como respuesta a una disminución de la credibilidad de las empresas debido al impacto bio-psico-social que estas generan en su búsqueda por incrementar su capital y obtener rentabilidad y cómo los actores: corporación, Estado y ciudadanos ceden responsabilidades y generan estructuras de poder ante la Responsabilidad Social que a cada uno le corresponde.

PALABRAS CLAVE: Responsabilidad Social Corporativa (RSC); grupos de interés; desarrollo social; desarrollo económico; neoliberalismo; ética empresarial.

\section{CORPORATE SOCIAL RESPONSIBILITY AND POWER STRUCTURE}

\section{Summary}

This article analyses of the origins of the phenomenon known as Corporate Social Responsibility (CSR) and how it has been decisive in the relationships of power between State and Enterprises. The CSR arises of the neoliberal model: Is a tendency to reduce state functions in a context-centric market, in reply to decline the credibility of the companies' bio-psycho-social impact they generate in the search for increase their capital and make profitability and how actors: corporation, state and citizens yield responsibilities and structures of power to generate social responsibility that everyone deserves.

KEYWORDS: Corporate Social Responsibility; business ethics; stakeholders; social development; economic development; neoliberalism; power structure. 


\section{INTRODUCCIÓN}

La Responsabilidad Social Corporativa (RSC) genera una sinergia entre la comunidad, empresa y Estado llevando a estos actores hacia un desequilibrio de estructuras de poder y responsabilidades en cuanto a sus roles. La RSC implica el fortalecimiento de la cohesión social, obligaciones y legislación del Estado, de lo cual revisaremos reseñas en el presente artículo, ya que cada uno de los actores debe desempeñar su rol de acuerdo a su posición y no perder su funcionalidad ya establecida para la sociedad.

Antecedentes asociados al neoliberalismo, desarrollo de comunidades y legislación han venido siendo constituyentes en el proceso de evolución de Responsabilidad Social Corporativa (RSC) a través de propuestas empresariales, legislación del Estado y contribución de la sociedad; todo esto visto desde un enfoque de equilibrio de estructuras de poder, responsabilidades y cohesión social.

\section{ENFOQUE Y METODOLOGÍA}

El enfoque epistemológico que principalmente se aplica a esta investigación documental es el Funcionalismo, desde la teoría sistémica (Malinowski y Radcliffe Brown), dado que el funcionalismo trata de explicar hechos antropológicos en todos los niveles de desarrollo, por el papel que desempeñan dentro del sistema total de la cultura, por la manera cómo se relacionan entre sí dentro del sistema y por la manera cómo este sistema se relaciona con el mundo físico.

Sin embargo, dada la orientación hacia los Derechos Humanos, la investigación también tiene un enfoque humanista, el cual trata de una actitud que intenta poner especial énfasis en la dignidad y el valor de la persona humana, considerándola como un ser racional, capaz de practicar el bien y encontrar la verdad.

La metodología utilizada es la investigación bibliográfica mediante el Constructivismo Social, inspirado por Vigotsky, el cual considera que el sujeto aprende de los demás a través de la interacción social, porque es un ser activo que, sustentado en una preconcepción teórica de la realidad, tiene la capacidad de ordenar, desordenar y organizar el conocimiento en su interior para luego exteriorizarlo a través de comportamientos. En este sentido, la realidad se construye socialmente y por tanto la Sociología del Conocimiento debe analizar los procesos por los cuales esto se produce".

\section{EL PODER DEL CAPITAL EN LOS ORÍGENES DE LA RESPONSA- BILIDAD SOCIAL}

El Modo de Producción Capitalista y su doctrina centrada en el Liberalismo Económico, se consolida en el Siglo XVIII, gracias a los aportes de Adam Smith, quien traslada al terreno de la economía las ideas de libertad, a partir de la publicación de su obra The Wealth of Nation (La riqueza de las naciones) en 1776. En ella se estableció la teoría de un sistema de libertades plenas para los individuos, con la posibilidad de que los hombres, cada cual persiguiendo su propio interés, consiguieran una armonía social y económica (Sartori, J. P., 1999).

Con el advenimiento del capitalismo primitivo en los años 1000 a 1300 D.C. se reportó un ascenso en la actividad comercial. Datan de este período los préstamos con cobro de intereses y la venta de mercancías a crédito... La Iglesia desarrolló una hostilidad hacia 
la actividad comercial, que tenía como fundamento, la creencia de que la dedicación al comercio alejada al hombre de la búsqueda de Dios, estimulando el interés propio y la obtención de riquezas. (Granadino, J. O., 2011).

El surgimiento del fenómeno de la Responsabilidad Social Corporativa (RSC) lo encontramos reflejado, en una primera etapa, estrechamente vinculada a las acciones filantrópicas u obras de caridad, primero realizadas a nivel individual por los empresarios y luego como aporte del management empresarial.

Carnegie (1993) expone que, en la fase final tardía del siglo XIX, algunas ideas relacionadas con RSE partieron de dos principios: el de caridad y el de custodia:

- Los dueños de las empresas tenían el papel de padres de los empleados y clientes, quienes carecían de capacidad para actuar en su propio bien. Este principio suponía que las empresas $\mathrm{y}$ los ricos fueran considerados custodios o administradores de los bienes terrenales. Según Carnegie (1993), los ricos tenían en "custodia" el dinero del resto de la sociedad y lo podían usar para cualquier propósito que la sociedad considerara legítima. No obstante también suponía que las empresas tenían el encargo de multiplicar la riqueza de la sociedad, incrementando la misma mediante la realización de inversiones prudentes de los recursos encomendados.

- Los miembros más afortunados de la sociedad debían ayudar a los menos afortunados: huérfanos, minusválidos, enfermos y personas de avanzada edad. Este principio convierte a las empresas en una especie de administradoras de los recursos sociales.
Los principios de caridad y custodia, fueron aceptados por las empresas norteamericanas, conforme fue aumentando la cantidad de compañías que reconocieron la máxima "el poder engendra responsabilidad", incluso las empresas que no apoyaban estos principios, sabían que si no aceptaban su responsabilidad social por voluntad propia, el gobierno las obligaría a aceptarla (Granadino, 2011).

Para la década de los 70, las estadísticas ya señalaban que de 250 empresas norteamericanas, el $12 \%$ ya contaba con departamentos de Asuntos Comunitarios y Sociales, con la finalidad de organizar e implementar sus acciones hacia la comunidad (Drucker, P. F., 1987).

Aun así, no es sino hasta el año 2002 que la RSC entra en la agenda del Foro Económico Mundial (WEF), en una sesión en la cual un grupo de presidentes y directores de diferentes corporaciones integrantes del WEF presenta una declaración conjunta, en la que recomiendan un marco para la acción en el ámbito de la RSE

\section{RSC EN EL DEBILITAMIENTO DEL ESTADO}

La RSC surge porque se había perdido el rol fundamental del Estado en servicio de las personas que residen en éste: la responsabilidad social como labor del Estado. Detrás de la RSC se esconde una nueva relación entre la sociedad y la empresa en función de solventar esta aparente y sensible debilidad del Estado.

La tendencia del neoliberalismo es la disolución del Estado, mientras que en el socialismo es el Estado el que está a cargo de todos los componentes de la sociedad. La misma empresa, en general, ha generado 
la idea de que el mundo debe ser mercadocentrista, es decir, está gobernado por la burguesía y por el comercio.

La RSC está relacionada con la tendencia a disminuir las funciones del Estado. Se está dejando a la empresa la función social que le corresponde al Estado. Las empresas tienen la responsabilidad de contribuir con acciones en beneficio de la sociedad, pero no es su función encargarse totalmente de esta labor.

Como efecto subsecuente del crecimiento del poder de las empresas, nos encontramos con una evidente disminución del poder de los Estados Nacionales. El modelo neoliberal, matizado con la influencia de la corriente económica del monetarismo, al pretender la construcción de un libre mercado mundial, impone a nuestros países, a través de organismos internacionales como el Banco Mundial $\mathrm{y}$ el Fondo Monetario Internacional, medidas como la apertura de mercados, desregulación económica, privatizaciones, etc. Todo esto trae como consecuencia importantes fuentes de obtención de ingresos para los Estados y, por ende, para la realización de las funciones públicas, entre estas, aquellas relacionadas con el bienestar social (Centro Cívico Democrático, 2006).

Por ello, Douglas Branson sitúa a las empresas como "cuasi estados", mientras que Capella las denomina "soberano privado supraestatal", conscientes de que las empresas compiten con el poder soberano de los estados. Este último se edifica desde el poder que ejerce un conjunto de grandes compañías transnacionales (conglomerados financieros) representadas en organizaciones o entidades de importancia mundial (Cámara de Comercio Internacional, Organización para la Coo- peración y el Desarrollo Económico OCDE, ONU, y más recientemente la Organización Mundial del Comercio OMC, entre otras) que inciden en la determinación de políticas económico sociales en el mundo.

Mir Puigpelat (2004) plantea la pérdida del poder de los Estados Nacionales ante el poder de las empresas transnacionales y los organismos internacionales, señalando la enorme presión que ejercen sobre los gobiernos mediante el atractivo de sus inversiones millonarias, lo cuallleva consigo una adaptación de las legislaciones medio ambientales y derecho laboral, que luego se ponen a tono, no con las necesidades que el género humano demanda, sino de los intereses económicos.

Presenciamos la inminente pérdida del poder de los Estados, no sólo en términos de decisión política, sino también en términos del margen de potestad de regulación jurídica que atrapa a los permeables poderes judiciales nacionales, sobre todo en los países en vías de desarrollo.

\section{LA RSC EN LA DISMINUCIÓN DE LA CREDIBILIDAD DE LAS EMPRESAS}

En el devenir histórico social, ya entrado el siglo XX, sobre todo en el contexto del crack de la bolsa de Wall Street que detonó la conocida crisis mundial de 1929, el sistema capitalista fundado en el liberalismo económico, cede terreno a un modelo con un papel más preponderante del Estado. Aparecen en este escenario, las teorías de John Maynard Keynes que propugnaron por un nuevo papel del Estado en la regulación de la actividad económica (Granadino, 2011).

En este contexto en el que el sistema capitalista está dando señales de debilidad y las grandes multinacionales están en 
el punto de mira, el concepto de RSC ha llenado los despachos de los departamentos de Marketing y Comunicación.

Pero este concepto, que algunos consideran una estrategia más de las empresas para vender y lavar su imagen, y otros un paso importante en la definición del papel de las empresas en la sociedad, se ha ido construyendo desde los años noventa, si bien la expresión nace en EE.UU. en los años cincuenta-sesenta.

Los valores sociales cambian proclamando la individualidad y la singularidad de cada persona, lo que acentúa la visión positiva de las empresas que se tornan como espacios de autorrealización y como agentes de desarrollo social. Los ciudadanos ven en ellas el lugar idóneo para la representación de sus intereses, necesidades y aspiraciones.

Ante la pérdida de confianza en las multinacionales y el progresivo decaimiento de la imagen de las grandes marcas, se empieza a replantear el papel de la empresa en la sociedad.

Así, desde los años noventa, el concepto de RSC ha ido cobrando fuerza y evolucionado tras el advenimiento de la globalización, el aceleramiento de la actividad económica, la conciencia ecológica y el desarrollo de nuevas tecnologías.

El contexto empresarial en el que nos situamos se caracteriza por una pérdida de confianza de la sociedad en las grandes empresas debido fundamentalmente a los escándalos financieros y la crisis económica. Además, los consumidores están ahora mejor formados, y esto se traduce en una mayor exigencia no sólo hacia los productos y/o servicios que se ofertan en el mercado, sino también ante el papel que deben desempeñar las empresas en la sociedad.
En general, las empresas debilitan los recursos de la sociedad, lo que disminuye su aceptación y credibilidad: se reducen los combustibles fósiles, se contaminan y disminuyen los caudales de los ríos, se talan muchos árboles, se contamina el medio ambiente, se disminuyen los recursos del mar.

Por otra parte, las empresas son las que predisponen los precios del mercado. El público no dejar de percibir la intención mercadológica implícita en algunas acciones relacionadas a la RSC.

Las situaciones sociales indeseables lo son también para las empresas, dado que disminuye la capacidad de compra, las instalaciones se vuelven menos atractivas. Cuando estas vuelven su mirada a la comunidad, ganan aceptación por parte de la población.

\section{EL ROL DEL ESTADO Y DE LAS EMPRESAS EN LA RESPON- SABILIDAD SOCIAL}

Toda persona, natural o jurídica, tiene una responsabilidad con la sociedad, no sólo de no causarle daño de algún tipo, sino de crear elementos orientados a la supervivencia y a la convivencia social.

Las naciones tienen mecanismos para hacer cumplir las normas de convivencia social entre las personerías naturales, y han establecido consecuencias y medidas disciplinarias para cuando estas normas no se cumplan. Al parecer, no ocurre lo mismo con las personerías jurídicas, cuando sin duda, el impacto de estas puede ser mucho mayor que el de las primeras.

Hacen falta reglamentos más determinantes y aplicaciones más específicas para hacer que las empresas no solamente no dañen el entorno psico-físico-social, sino que cumplan con su responsabilidad 
de crear elementos favorecedores de la dinámica humana.

\section{a. Rol del Estado}

Es el Estado quien debe encargarse del bienestar social. Los problemas económicos y sociales, entre ellos la pobreza extrema, la desigualdad social, el analfabetismo, entre otros, en lugar de desaparecer, según informes de los más importantes organismos mundiales, parecen incrementarse o también "globalizarse". Sumado a ello, los escándalos en materia de fraudes financieros, corrupción, violación de derechos humanos, laborales y medioambientales, entre otros, harán que las empresas, los gobiernos y las organizaciones de la sociedad civil reflexionen nuevamente acerca del papel y la responsabilidad de las empresas con respecto a los stakeholders, comunidad y entorno, en aras de garantizar la construcción de un nuevo modelo económico sostenible que incluya el aspecto del desarrollo social en su total dimensionamiento.

\section{b. Rol de la ciudadanía}

Es importante que sea la comunidad la que controle la empresa y no la empresa la que controle la sociedad. Si se privatizan los servicios públicos, la posibilidad de participar desde la ciudadanía es muy distinta, pues la empresa mantiene su función pública pero su gestión es privada; su objeto de mercado se convierte, porque es una relación de costo-beneficio que no se relaciona con los derechos humanos, y entonces, es ahí cuando se cuestiona el concepto real de responsabilidad social en una empresa de servicios públicos.

Para una empresa de servicios públicos no existe un riesgo muy grande de responsabilidad social cuando la donación que se realiza se hace antes de la declaración de impuestos (las donaciones son deducibles de los impuestos de renta que tiene que pagar la empresa). Pero en el contexto social existe otro tipo de problema, el cual consiste en que los dineros que tenían el direccionamiento para los impuesto -los cuales se iban a destinar a aspectos globales y locales del país que, a su vez, el Ejecutivo decidiría vía legislativa en qué lo invertían de acuerdo con una lógica de vulnerabilidad, prioridades y necesidades de la población-, la empresa es la que decide finalmente a dónde invierte los recursos sin consultarlo con la ciudadanía, y es aquí donde se demuestran las formas limitadas de participación.

De otro lado, la realidad es que cada empresa decide las políticas públicas de su área, su entorno, sus clientes, su imagen, volviéndose publicidad lo que es una donación. o peor aún, se vuelve en un gasto sin que el público decida algo que hace parte de lo público. Por esta razón es importante que las empresas se preocupen de este tipo de temas y de tener un estándar de derechos humanos en los servicios (PNUD, 2010).

\section{c. Rol de las empresas}

Se ha comentado que el interés de la empresa debiera estar, más que en la responsabilidad social (RSE), en generar facilidad, exigir transparencia y eficiencia al gobierno, de manera que sea este último -y no la empresa- el que actúe en el plano social para solucionar los problemas que afrontan las comunidades.

Con esta afirmación, pareciera entenderse que la RSC está circunscrita únicamente a los proyectos sociales que la empresa desarrolla en favor de las comunidades donde opera.

En este mismo escenario de gestión de impactos del negocio, la RSC promueve que las empresas cumplan su rol económico 
(ser rentables), pero en el marco de la ley y de la ética (curiosamente, lo mismo que proponía Milton Friedman), y que quede a discreción de sus directivos y accionistas el modo en que quiera ejercer una ciudadanía corporativa que la lleve a trabajar por otros objetivos de largo plazo más amplios en favor de la sociedad. En este entendido, cuando la empresa se ocupe de iniciativas sociales más amplias (donde idealmente debiera trabajar en alianza con el Estado y la sociedad civil), debiera centrarse en proyectos que mejoren las condiciones del mercado en el que opera y así, al mismo tiempo, reforzar su competitividad en el largo plazo.

\section{LEGISLACIÓN}

Conviene que el Estado defina una Ley de Responsabilidad Social y la relación de ésta con el Estado y las empresas.

Las normas de RSC se vuelven un imperativo social, una herramienta que debería ser consustancial al mismo sistema capitalista, ya que se señala las nuevas reglas de comportamiento a seguir por las empresas de cara a la construcción de sistemas económicos sociales que tengan como punto de partida y de llegada el diálogo social entre los principales actores, poniendo énfasis en el antropocentrismo o en el mercado- centrismo en conjunto con la cohesión social.

Será necesario, además, en el desarrollo de la teoría de la competencia y los checks and balances, ante el aparecimiento de este nuevo bloque de poder, público y privado, representado por los organismos internacionales y las empresas privadas (diferente a los Estados y a veces por sobre los Estados), anteponer otros bloques de poder que solo pueden descansar, en este caso, en la sociedad civil organizada.
En el nivel predictivo de la ciencia, no sabemos aún si la asunción integral de la RSC dentro del Modo de Producción Capitalista, se constituya en una faceta preliminar de un nuevo Modo de Producción con relaciones sociales cercanas a los ideales de justicia; lo que sí podemos afirmar es que la asunción de la RSC se vuelve un elemento imprescindible de cohesión social.

\section{El sindicato como parte de respon- sabilidad social empleado-empresa} ¿Qué papel juega el sindicato y sus representantes en la empresa? El sindicato tiene una posición peculiar como grupo de interés en representación de las personas en la empresa: es el único sujeto social que está organizado, simultáneamente, en la empresa y en la sociedad. En relación a lo que denominaríamos responsabilidad social interna, es decir, del empresario hacia las personas que trabajan en la empresa, el sindicalismo es un interlocutor exclusivo.

\section{EL LEGADO SOCIAL DE LAS CORPORACIONES}

El concepto moderno de RSC enfatiza, en un sentido bastante amplio, en la necesidad de que la empresa gestione de manera responsable los diversos impactos que se producen como resultado de las decisiones que estas y otros toman en su operatividad diaria. De esta manera se pretende el balance final de que su presencia en el mercado sea positivo para la sociedad. Y cuando nos referimos a otros, incluimos por supuesto a la comunidad, pero también nos referimos a sus trabajadores, a sus proveedores, a sus socios comerciales, a su propio equipo directivo, a sus acreedores, al Estado, a sus competidores, a las organizaciones de la sociedad civil y a cualquier otro actor que se vea afectado con el accionar de esta sinergia. 
Si utilizamos esta visión amplia de la gestión responsable de las relaciones de la empresa con sus diversos grupos de interés (y para hablar en lenguaje empresarial, la mejor gestión de los riesgos del negocio), veremos que los proyectos con la comunidad son solo un elemento dentro de la cartera de objetivos que se pueden plantear en un plan de RSE.

\section{CONCLUSIÓN}

Es el Estado el legislador, coordinador y ejecutor de la responsabilidad social $\mathrm{y}$ esta función debe ejercerla en base a sus lineamientos y responsabilidades, creando también desarrollo del capital, generando sinergia entre el apoyo de todos los actores a través de la RSC, con propuestas empresariales orientadas a que cada uno de ellos desarrolle su rol fundamental y no generar desequilibrio en responsabilidades y en las estructuras de poder.

\section{FUENTES CONSULTADAS}

SARTORI, J. P. 1999, Elementos de Teoría Política, Alianza Editorial, Madrid.

Granadino, Julio Olivo, Diciembre 2011, El ocaso de las empresas socialmente irresponsables, Editorial Universitaria Universidad de El Salvador.

Carnegie, A. 1993, The gospel of wealth. Essay of fhilanthropy. Indiana University.

Drucker, P. F. 1987, Post Capitalist Society, Editorial Linacre House, Jordan Hill, Oxford.

PNUD, Mayo de 2010, Memorias del Seminario de participación ciudadana y servicios públicos. Área de Paz, Desarrollo y Reconciliación, Proyecto Derechos y Desarrollo, Bogotá, Colombia.

Centro Cívico Democrático, 2006, Hacia la justicia Social, Boletín, año XIII, No. 608.

González Marroquín, G., 2003, "El ser humano hace la diferencia”. Ponencia presentada en el V Congreso Nacional e Internacional de ADOARH, Chile.

Oriol Mir Puigpeat, 2004, Globalización y estado de derecho. CIVITAS EDICIONES, S.L. 